\title{
Predictors of Human Papilloma Virus Vaccination Uptake among Female University Students in Turkey
}

\author{
Illker Kayı1 (D), Gökçe Yavaş² (D), Bahar Ezgi Uçurum³ (D), Pelinsu Yılmaz ${ }^{4}$ (D), Betül Gökçek ${ }^{5}$ (D), \\ Şeyda Ece Oğuzer ${ }^{6}$, Buse Eğlenen", Önder Ergönül8 (D) \\ 1 Department of Public Health, Koç University School of Medicine, İstanbul, Turkey \\ 2 Department of Obstetric \& Gynecology, Osmangazi University School of Medicine, Eskişehir, Turkey \\ 3 Department of Otolaryngology, Uludağ University School of Medicine, Bursa, Turkey \\ 4 Department of Dermatology, Augsburg University School of Medicine, Augsburg, Germany \\ 5 Department of Ophthalmology, Atatürk University School of Medicine, Erzurum, Turkey \\ 6 Department of Dermatology, Karadeniz Technical University School of Medicine, Trabzon, Turkey \\ 7 University of Texas Southwestern Medical Center, Dallas, TX, USA \\ 8 Department of Infectious Diseases and Clinical Microbiology, Koç University School of Medicine, İstanbul, Turkey
}

\begin{abstract}
Introduction: Human Papilloma Virus (HPV) vaccine provides a primary prevention opportunity to decrease the morbidity and mortality of cervical cancer. Turkey has not yet included it in the national immunization program, but it is commercially available. We aimed to explore the predictors of HPV vaccine uptake among female students in a university in Turkey.

Methods: This is a cross-sectional survey conducted with 1,115 female students via a questionnaire assessing the sociodemographic characteristics, vaccination uptake, knowledge and attitudes towards HPV and related conditions.

Results: $75.2 \%(n=838)$ of the participants reported hearing HPV vaccine and $17.9 \%(n=200)$ reported they had received at least one dose of HPV vaccine. The median knowledge score was 6 out of 10. Multivariate analysis showed that age (OR: 1.181; 95\% CI 1.070-1.304), knowledge score (OR: 1.183; 95\% CI 1.075-1.302), department (OR: 1.667; 95\% CI 1.0872.557), sexual activity (OR: 2.384; 95\% CI 1.596-3.561), and level of family income (OR: 3.205; 95\% CI 2.066-4.970), were significantly associated with vaccination uptake.

Conclusion: Our study indicates that the cost of HPV vaccines is an important barrier to equitable access to vaccines. Policies ensuring equitable access and raising awareness has the potential to promote the vaccination uptake among youth.
\end{abstract}

Keywords: Attitude, knowledge, affordability, barriers, developing country

\section{INTRODUCTION}

ervical cancer is the fourth leading cause of all cancers among women globally, and $90 \%$ of all deaths occur in low- and middle-income countries. Sexual intercourse is the main route of transmission for HPV infection. The course of HPV in-
Corresponding Author: ilker Kayı

\section{E-mail:}

ikayi@ku.edu.tr

Received: December 3, 2020 Accepted: December 28, 2020 Published: December 31, 2020

\section{Suggested citation:}

Kayı İ, Yavaş G, Uçurum BE, Yılmaz P, Gökçek B, Oğuzer

ŞE, et al. Predictors of Human Papilloma Virus Vaccination Uptake among Female University Students in Turkey. Infect Dis Clin Microbiol 2020; 3: 138-146.

DOI: $10.36519 / \mathrm{idcm} .2020 .0030$ 
fection differs according to the HPV type, immune status of the women, coinfections with other sexually transmitted infections (STIs), number of parity and smoking habit. There is a risk of developing a chronic infection, which then might lead to cervical cancer (1).

The vaccination for HPV virus is the primary prevention measure for HPV related cervical cancers. They provide further benefits for HPV infected women by reducing the risk of relapse after clinical treatment of the disease (2). There are bivalent, quadrivalent, and nine-valent HPV vaccines, all including HPV types 16 and 18 that cause most cervical cancers (3). National level coverage of vaccines globally is under $80 \%$, although they are all proved to be highly protective against cervical cancers (4).

The HPV vaccine is not included in the national vaccination program in Turkey yet; however, the HPV vaccines are commercially available in bivalent and quadrivalent forms. This study aimed to investigate the awareness of and attitude towards HPV vaccination and describe the reasons for not getting vaccinated among a study population of female university students.

\section{MATERIALS AND METHODS}

This is a cross-sectional study conducted in 2015 among female students in a private university in Istanbul, Turkey. Initially, female interviewers (also co-authors GY, BEU, PY, BG, ŞEO, BE) administered

\section{HIGHLIGHTS}

- HPV vaccination uptake among female university students is considerably low compared to western countries, however it is higher than other universities in Turkey.

- Being sexually active and high-income level contributed the most to the increased uptake of HPV vaccination.

- Cost of the vaccine poses a barrier in access to HPV vaccination in a context where the vaccine is not included in the national immunization program. the survey face-to-face for two months. After two months, we stopped the interviews and sent an email with an online survey link developed in Qualtrics ${ }^{\mathrm{TM}}$ to all female students in the university that was open for participation for an additional one month. Data collection was completed in three months. In order to prevent duplications, we had inserted a reminder of whether the participant had completed the questionnaire via a face-to-face interview before. When the participant gave a positive response, the online questionnaire automatically skipped the survey and finished the session.

The survey consisted of 25 questions on sociodemographics, sexual activity, safe sex practices, history of STIs and vaccine awareness and attitude. Vaccine awareness was assessed via 10 true or false questions, and attitude was assessed based on the participant's vaccination status. Positive attitude was accepted if the participant initiated or completed the HPV vaccination based on selfreport. Data collection started after obtaining ethical approval for the study from the Institutional Review Board of the same university. We obtained informed consent from each participant signing the form either by the initials of their name and surname or by using a pseudonym. To ensure the confidentiality and security of sensitive data, no personal identification information were collected in the questionnaire.

Statistical analysis was performed by using SPSS (V26.0). Continuous variables were summarized with their mean and standard deviation and categorical variables with percentages. We performed a Chi-Square test for univariate analysis, and we designed a logistic regression model with the variables showing significant association for multi-variate analysis. The variables that were significant in univariate analysis were included to the multi-variate model. Hosmer \& Lemeshow test was used to assess the goodness-of-fit of the model. Statistical significance was accepted as $\mathrm{p}<0.05$.

\section{RESULTS}

In total, 1115 female students out of 2897 participated in the study with a response rate of $38.7 \%$. The mean age was 20.8 (SD=1.98), and the median 
Table 1. HPV vaccine awareness and vaccination status (receiving at least one dose of HPV vaccine) according to sociodemographic characteristics and reproductive health status.

\begin{tabular}{|c|c|c|c|c|c|c|c|}
\hline & \multicolumn{3}{|c|}{ Heard of HPV Vaccine } & \multicolumn{3}{|c|}{ Vaccinated with HPV Vaccine } & \multirow{2}{*}{$\begin{array}{l}\text { Total } \\
\mathrm{N}(\%)\end{array}$} \\
\hline & No & Yes & $\mathrm{p}$ & No & Yes & $\mathrm{p}$ & \\
\hline \multicolumn{8}{|l|}{ Age } \\
\hline 19 and below & $121(36.6 \%)$ & $210(63.4 \%)$ & \multirow{2}{*}{$<0.001$} & $293(88.5 \%)$ & $38(11.5 \%)$ & \multirow{2}{*}{$<0.001$} & $331(100 \%)$ \\
\hline 20 and above & $153(19.5 \%)$ & $631(80.5 \%)$ & & $622(79.3 \%)$ & $162(20.7 \%)$ & & $784(100 \%)$ \\
\hline \multicolumn{8}{|l|}{ Monthly Family Income } \\
\hline$\$ 2,499$ and below & $103(30.4 \%)$ & $236(69.6 \%)$ & \multirow{3}{*}{$<0.001$} & $304(89.7 \%)$ & $35(10.3 \%)$ & \multirow{3}{*}{$<0.001$} & $339(100 \%)$ \\
\hline$\$ 2,500$ and above & $78(17.3 \%)$ & $373(82.7 \%)$ & & $339(75.2 \%)$ & $112(24.8 \%)$ & & $451(100 \%)$ \\
\hline No answer & $93(28.6 \%)$ & $232(71.4 \%)$ & & $272(83.7 \%)$ & $53(16.3 \%)$ & & $325(100 \%)$ \\
\hline \multicolumn{8}{|l|}{ Department } \\
\hline Medicine & $15(17.9 \%)$ & $69(82.1 \%)$ & \multirow{5}{*}{0.001} & $71(84.5 \%)$ & $13(15.5 \%)$ & \multirow{5}{*}{0.023} & $84(100 \%)$ \\
\hline Law & $28(22.6 \%)$ & $96(77.4 \%)$ & & $98(79.0 \%)$ & $26(21.0 \%)$ & & $124(100 \%)$ \\
\hline Social Sciences \& Humanities & $40(17.5 \%)$ & $189(82.5 \%)$ & & $173(75.5 \%)$ & $56(24.5 \%)$ & & $229(100 \%)$ \\
\hline Science \& Engineering & $107(32.1 \%)$ & $226(67.9 \%)$ & & $286(85.9 \%)$ & $47(14.1 \%)$ & & $333(100 \%)$ \\
\hline Administration \& Economics & $84(24.3 \%)$ & $261(75.7 \%)$ & & $71(84.5 \%)$ & $13(15.5 \%)$ & & $345(100 \%)$ \\
\hline \multicolumn{8}{|l|}{ Sexually active } \\
\hline No & $199(29.4 \%)$ & $478(70.6 \%)$ & \multirow{2}{*}{$<0.001$} & $590(87.1 \%)$ & 87 (12.9\%) & \multirow{2}{*}{$<0.001$} & $677(100 \%)$ \\
\hline Yes & 75 (17.1\%) & $363(82.9 \%)$ & & 325 (74.2\%) & $113(25.8 \%)$ & & $438(100 \%)$ \\
\hline \multicolumn{8}{|l|}{${ }^{\star}$ Condom use } \\
\hline Never-Sometimes & $43(15.4 \%)$ & $236(84.6 \%)$ & \multirow{2}{*}{0.208} & 200 (71.7\%) & $79(28.3 \%)$ & \multirow{2}{*}{0.111} & $279(100 \%)$ \\
\hline Always & $32(20.1 \%)$ & $127(79.9 \%)$ & & $125(78.6 \%)$ & $34(21.4 \%)$ & & $159(100 \%)$ \\
\hline \multicolumn{8}{|l|}{$\begin{array}{l}{ }^{*} \text { Previously diagnosed } \\
\text { STI }\end{array}$} \\
\hline No & $73(17.8 \%)$ & $336(82.2 \%)$ & \multirow{2}{*}{$0.199^{\star \star}$} & 309 (75.6\%) & $100(24.4 \%)$ & \multirow{2}{*}{0.015} & $409(100 \%)$ \\
\hline Yes & $2(6.9 \%)$ & 27 (93.1\%) & & $16(55.2 \%)$ & $13(44.8 \%)$ & & $29(100 \%)$ \\
\hline \multicolumn{8}{|l|}{$\begin{array}{l}\text { *Previously diagnosed } \\
\text { HPV infection }\end{array}$} \\
\hline No & 75 (17.9\%) & $343(82.1 \%)$ & \multirow{2}{*}{$0.033^{* *}$} & 315 (75.4\%) & $103(24.6 \%)$ & \multirow{2}{*}{0.011} & $418(100 \%)$ \\
\hline Yes & $0(0 \%)$ & $20(100.0 \%)$ & & $10(50.0 \%)$ & $10(50.0 \%)$ & & $20(100 \%)$ \\
\hline
\end{tabular}

*Analysis have been conducted among sexually active participants ( $\mathrm{N}=438)$.

**Fisher Exact Test result. 
age was 21. Among the participants $7.5 \%(\mathrm{n}=84)$ were from school of medicine, $30.9 \%(n=345)$ were from department of administration and economics, $29.9 \%$ ( $n=333)$ from science and engineering department, $20.5 \% \quad(n=229)$ from department of social sciences and humanities, and $11.1 \%(n=124)$ from department of law. While $40.4 \%$ of the participants ( $\mathrm{N}=451)$ reported a monthly family income of 7000 TRY (equivalent to $\$ 2,500$ with a currency of $\$ 1$ equal to $2.8 \mathrm{TRY}$ during the time of study) and above $29.2 \%(\mathrm{~N}=325)$ did not provide an answer to income question.

In total, $39.8 \%$ of the participants reported being sexually active. Sexual activity among the participants from social science and humanities was $52 \%$, while all the other departments ranged between $29 \%$ and $39.9 \% \quad(p<0.001)$. Thirty-six percent of the sexually active participants reported using a condom on all occasions. The $6.6 \%(n=29)$ of the sexually active group reported a history of sexually transmitted disease, and $4.6 \%(n=20)$ had HPV diagnosis previously.
In total, $75.2 \% \quad(\mathrm{n}=838)$ reported hearing HPV vaccine and $17.9 \%(n=200)$ received at least one dose of HPV vaccine. Table 1 summarizes the HPV awareness and vaccination status according to the participants' sociodemographic characteristics and reproductive health status.

In three of the questions (items 1,5 and 7) that evaluated the level of participants' knowledge on HPV infection, cervix cancer, and HPV vaccine less than half of the sample answered correctly (Table 2). Sixty-eight participants (6.1\%) could not provide any correct answers, and 39 participants (3.5\%) responded to all questions correctly. In total, $21.1 \%$ of the participants $(\mathrm{N}=235)$ responded to less than half of the questions (0-4 items) correctly.

The mean total score was 5.96 ( $\mathrm{SD}=2.43)$, and median was 6 . The mean total score of the students aged 19 and below, and the ones aged 20 and over were $5.75(\mathrm{SD}=2.37)$ and $6.05(\mathrm{SD}=2.45)$, respectively $(p=0.045)$. Students who were sexually active scored with a mean of $6.27(S D=2.20)$, while the ones who

Table 2. Knowledge of HPV infection, cervix cancer and HPV vaccine $(\mathrm{N}=1,115)$

\begin{tabular}{|c|c|c|}
\hline Items & $\begin{array}{c}\text { Incorrect } \\
\mathrm{N}(\%)\end{array}$ & $\begin{array}{c}\text { Correct } \\
\mathrm{N}(\%)\end{array}$ \\
\hline 1) HPV vaccine and cervix cancer vaccine are the same (T). & $826(74.1 \%)$ & $289(25.9 \%)$ \\
\hline 2) HPV causes cervix cancer $(T)$. & $432(38.7 \%)$ & $683(61.3 \%)$ \\
\hline 3) HPV vaccine is recommended for women over 30 years of age (F). & $316(28.3 \%)$ & $799(71.7 \%)$ \\
\hline 4) HPV vaccine is recommended to be administered in 3 doses $(T)$. & $287(25.7 \%)$ & $828(74.3 \%)$ \\
\hline 5) HPV vaccine is recommended before first sexual intercourse (T). & $59153.0(\%)$ & $524(47.0 \%)$ \\
\hline 6) Nulliparous women have no chance of getting cervix cancer (F). & $140(12.6 \%)$ & $975(87.4 \%)$ \\
\hline 7) Cervix cancer is transmitted through sexual intercourse (F). & $653(58.6 \%)$ & $462(41.4 \%)$ \\
\hline 8) Condom use does not decrease the chance of getting cervix cancer (F). & $457(41.0 \%)$ & $658(59.0 \%)$ \\
\hline 9) All types of HPV infection progress to cervix cancer (F). & $352(31.6 \%)$ & $763(68.4 \%)$ \\
\hline 10) HPV may cause infertility $(T)$. & $451(40.4 \%)$ & $664(59.6 \%)$ \\
\hline
\end{tabular}

T: True; F: False 
Table 3. Logistic regression model for getting vaccinated with HPV vaccine

\begin{tabular}{|l|c|c|}
\hline Covariates in the model & OR & $95 \% \mathrm{Cl}$ \\
\hline Age & 1.181 & $1.070-1.304$ \\
\hline Total score of true-false questions & 1.183 & $1.075-1.302$ \\
\hline $\begin{array}{l}\text { Department of social sciences \& } \\
\text { humanities }\end{array}$ & 1.667 & $1.087-2.557$ \\
\hline \begin{tabular}{l} 
Being sexually active \\
\hline $\begin{array}{l}\text { Monthly family income of } \$ 2,500 \\
\text { and above }\end{array}$
\end{tabular} & 2.384 & $1.596-3.561$ \\
\hline
\end{tabular}

reported no sexual activity scored with a mean of $5.76(\mathrm{SD}=2.56)(\mathrm{p}=0.005)$.

The association between vaccination status (receiving at least one dose of HPV vaccine) and the covariates that have a significant association in univariate analysis (age, knowledge test score, department, sexual activity, and monthly family income) was further analyzed in a logistic regression model (Table 3). The Hosmer \& Lemeshow test indicated a good fit for our model ( $p=0.221)$

Participants' reasons for not getting vaccinated with the HPV vaccine are summarized in Table 4 according to sexual activity. After excluding the ones who received at least one dose of the vaccine, 6 participants $(0.7 \%)$ reported that their reason for not getting the vaccination was religious exemptions; 20 participants $(2.2 \%)$ reported that they do not believe in the protective effect of the vaccine; 274 participants (29.9\%) reported that they have never heard of the vaccine; 328 participants $(35.8 \%)$ indicated that they would be vaccinated in the future.

\section{DISCUSSION}

The HPV vaccine has been approved to be administered to prevent cervix cancer in women in 2006 in the United States of America (USA) and it was available in Turkey soon after its introduction in the global market. Until the introduction of HPV vaccines globally, the most common prevention strategy for cervical cancers was screening programs for early diagnosis and early treatment. Since 2004 the Turkish Ministry of Health $(\mathrm{MoH})$ has been implementing a PAP Smear screening program for women over 30 years of age, however, the coverage rate of the program was below $2 \%$. In 2014 the MoH switched to an HPV DNA screening program that has increased the coverage 5-6 times more compared to the cytology-based program and the results of the HPV DNA screening showed that the most common serotypes were 16, 51, 31, 52 and 18 (5). Nevertheless, Turkish MoH has not introduced HPV vaccination into routine vaccination program as a preventive intervention. One reason is that the incidence rate of cervix cancer remains low at 5.7 per 100,000 (6) compared to 11.2 per 100,000 in the European Region (7).

Our findings indicate that the uptake of HPV vaccination among female students in a university is considerably low, with a percentage of $17.9 \%$, while the awareness of such a vaccine availability constitutes 75.2\%. Williams et al. (2013) reported similar results among young women in the USA in a national sample, and the percentage of women who have heard of the vaccine was $72.8 \%$, while the ones who have received at least one dose of the vaccine was 18.0\% (8). Bednarczyk et al. (2011) showed a higher ratio of female university students in the USA as 55.6\% to receive the vaccination (9) while another study in the US among university students have shown the increasing trend of vaccination uptake between 2009 and 2013 from 44.7\% to 68.9\% (10). In a recent study conducted among undergraduate level healthcare university students in Switzerland, $72.6 \%$ of female students have been reported to receive at least one dose of HPV vaccination (11). In our study the level of vaccination uptake among medical students was $15.5 \%$, which is considerably lower compared to the report from Switzerland (11), although it could be even higher than other universities in Turkey. The uptake of HPV vaccination was found $1.5 \%$ among university students in two different public universities in Turkey $(12,13)$. In an earlier study from a public university in Turkey, the vaccination rate was $0.3 \%$ among 800 female university students (14).

Increasing age was significantly associated with an increased likelihood of vaccination uptake in our 
Table 4. Reasons for not getting vaccinated with HPV vaccine ( $N=915$ after the participants who received vaccination has been excluded).

\begin{tabular}{|c|c|c|c|c|c|}
\hline \multirow{2}{*}{ Reasons } & \multicolumn{3}{|c|}{ Sexually active } & \multirow[b]{2}{*}{ Total } & \multirow[b]{2}{*}{$\mathrm{p}$} \\
\hline & & Not active $\mathrm{N}(\%)$ & Active $\mathrm{N}(\%)$ & & \\
\hline \multirow{2}{*}{ Heard of HPV vaccine. } & No & $199(33.7 \%)$ & $75(23.1 \%)$ & $274(29.9 \%)$ & \multirow{2}{*}{0.001} \\
\hline & Yes & $391(66.3 \%)$ & $250(76.9 \%)$ & $641(70.1 \%)$ & \\
\hline \multirow{2}{*}{ Willingness to receive vaccination in the future. } & No & $399(67.6 \%)$ & $188(57.8 \%)$ & $598(64.2 \%)$ & \multirow{2}{*}{0.003} \\
\hline & Yes & $191(32.4 \%)$ & $137(42.2 \%)$ & $328(35.8 \%)$ & \\
\hline \multirow{2}{*}{ Finds the price of the vaccine expensive. } & No & $577(97.8 \%)$ & $299(92.0 \%)$ & $876(95.7 \%)$ & \multirow{2}{*}{$<0.001$} \\
\hline & Yes & $13(2.2 \%)$ & $26(8.0 \%)$ & $39(4.3 \%)$ & \\
\hline \multirow{2}{*}{ Does not believe the vaccine is protective. } & No & $580(98.3 \%)$ & $315(96.9 \%)$ & $895(97.8 \%)$ & \multirow{2}{*}{0.171} \\
\hline & Yes & $10(1.7 \%)$ & $10(3.1 \%)$ & $20(2.2 \%)$ & \\
\hline \multirow{2}{*}{ Skeptic about the safety of the vaccine. } & No & $467(79.2 \%)$ & $243(74.8 \%)$ & $710(77.6 \%)$ & \multirow{2}{*}{0.128} \\
\hline & Yes & $123(20.8 \%)$ & $82(25.2 \%)$ & 205 (22.4\%) & \\
\hline \multirow{2}{*}{ Does not consider herself in the risk group. } & No & 447 (75.8\%) & $278(85.5 \%)$ & 725 (79.2\%) & \multirow{2}{*}{$<0.001$} \\
\hline & Yes & $143(24.2 \%)$ & $47(14.5 \%)$ & $190(20.8 \%)$ & \\
\hline \multirow{2}{*}{ Religious exemptions. } & No & $586(99.3 \%)$ & $323(99.4 \%)$ & $909(99.3 \%)$ & \multirow{2}{*}{$0.637^{\star}$} \\
\hline & Yes & $4(0.7 \%)$ & $2(0.6 \%)$ & $6(0.7 \%)$ & \\
\hline
\end{tabular}

*Fisher Exact Test result.

study. In a systematic review by Kessels et al. (2012), the age of initiation to HPVvaccine was more common in early ages and the level of initiation declined after 17 years of age (15). Similarly, Altobelli et al. (2018) has reported that in high-income countries, especially where HPV vaccination is included in the national immunization programs, HPV vaccination uptake is higher among females before 18 years of age (16). In South Africa, a low- and middle-income country, willingness to get vaccinated was higher among younger age groups as well (17). A US-based representative study among 18-24-year-old youth by Rahman et al. (2015) indicated that vaccination uptake was higher among younger women (18). However, in another study from the US with a representative sample of college students aged 1826 years, Thompson et al. (2016) reported that there had been an increase in vaccination uptake with age (10). Also, a recent multicenter study from China reported an increasing trend of vaccination uptake by age among female college students, with a sharp increase after 23 years of age (19).
Studies focusing on universities from geographically diverse locations such as the USA (20), Lebanon (21) and China (22) consistently showed significantly higher knowledge scores among vaccinated students. The systematic review by Kessels et al. (2012) reported that a high level of knowledge was associated with higher uptake of the HPV vaccine (15). We found that increasing knowledge of HPV vaccine and HPV associated diseases have a significant association with vaccination uptake (OR: 1.18, 95\% CI 1.075-1.308) and sexual activity (OR: 2.38, 95\% CI 1.596-3.561). There have been similar findings from cross-sectional studies showing a significant association between vaccination uptake and sexual activity $(9,11,13,23)$ as well as no association (24). According to a study by Villanueva et al. (2019), among nursing school students, there was a significant association between sexual activity and increased odds for the level of knowledge, but no significant association with a positive attitude towards HPV vaccination (25). In our study, the total score in the knowledge test was significantly 
higher in both the sexually active group and the age group 20 and above; therefore, we propose that increasing age along with high scores in knowledge test might have created a higher risk perception that would increase their likelihood to receive the HPV vaccination.

Agostie and Goldie (2007) argue that the most critical barrier to access to the HPV vaccine is the cost (26). We found that income is the strongest predictor of HPV vaccination uptake with an OR of 3.20 (95\% CI 2.066-4,970). Conroy et al. (2009) indicated that the low-income level was associated with lack of insurance, which then became a barrier to vaccination (27). Similarly, Dempsey et al. (2010) and Williams et al. (2013) found that level of vaccination uptake was associated with insurance coverage providing free access to HPV vaccines $(8,28)$. As mentioned earlier HPV vaccines are not included in the national immunization program, but HPV vaccines are available only in bivalent and quadrivalent forms in pharmacies for a price of approximately $\$ 90$ per dose. Unless the vaccine becomes more affordable or is included in the immunization program, the price of the vaccine seems to cause an inequitable access.

Williams et al. (2013) reported that not needing the vaccine (first) and safety concerns (second) as the leading reasons for not receiving the vaccine (8). In our study, the first reason reported was willingness to vaccinate in the future followed by safety concerns and not considering herself in the risk group. Widjaja et al. reported price as the number one reason for rejecting the vaccination, followed by safety concerns (29). Kang and Moneyham showed that Korean students also had safety concerns and had a low level of perception for need (30). Another study by Bednarczyk et al. (2011) reported that besides safety concerns and the cost, the lack of doctor recommendation and low perception of the need due to not having sex were also critical (9). In Turkey, it can be said that it is common to recommend HPV vaccines among gynecologists (31). In our study, among the group who had not received the HPV vaccination, $35.8 \%$ reported their willingness to get the vaccination in the future. This ratio was significantly higher among the unvaccinated sexually active students. Again, the same group had a significantly higher awareness of the vaccine than unvaccinated students without reporting sexual activity. Although income was the strongest predictor of being vaccinated in the whole group, the price of the vaccine was found to be expensive by only $3.4 \%$ among the unvaccinated with a significantly higher ratio among the sexually active group. In addition, in the whole unvaccinated sample, the ratio of sexually active women was significantly higher.

This study is subject to several limitations. Firstly, this is a single-center study that was conducted in a non-profit private foundation university, which may not represent the university student population of the country in terms of vaccination rate. However, the vaccination rate was already low, and we expect much lower in the other universities and in the community. Secondly, we did not select the subject with a randomized method, but we tried to reach out to the students as much as possible and as a result we achieved a high response rate. Despite its limitations, our study has a high response rate with more than 1,100 participants, allowing us to draw stable estimates from the data. Also, to our knowledge, it is the first study to analyze vaccination uptake and related factors to show the disparities in access to HPV vaccine among female university students in Turkey.

\section{CONCLUSION}

Being sexually active and a high-income level emerged as the leading factors for the increased uptake of HPV vaccination in our study. Increased age and knowledge, together with beginning of sexual activity, seem to increase the perceived risk among female university students. Considering the low coverage level of HPV screening program in Turkey, HPV vaccination provides an opportunity to prevent HPV-related diseases, including cervical cancer. However, in a context where the vaccine is not included in the national immunization program, the vaccine's cost may pose a strong barrier to ensuring equitable access to HPV vaccines. Policies and interventions to raise awareness might increase the demand for HPV vaccines. Besides, reducing the cost of the vaccines via different cost reduction mechanisms would increase the access. 
Ethical Approval: Koc University Institutional Review Board approved the study with the approval number of 2014.135. IRB2.037.

Peer-review: Externally peer-reviewed

Author Contributions: Concept - İ.K., G.Y., B.E.C., P.Y., B.G., E.O., B.E., O.E.; Design - I.K., G.Y., B.E.C., P.Y., B.G., E.O., B.E., O.E.; Supervision - İ.K., O.E.; Data Collection and/or Processing - G.Y., B.E.C., P.Y., B.G., E.O., B.E.; Analysis and/or Interpretation - İ.K., O.E.; Literature Review - G.Y., B.E.C., P.Y., B.G., E.O., B.E.; Writer - İ.K.; Critical Reviews - O.E.
Conflict of Interest: The authors have no conflict of interest to declare.

Financial Disclosure: The authors declared that this study has received no financial support.

Acknowledgements: The authors would like to thank Prof. Sibel Sakarya for critically reading and providing suggestions that helped clarify the manuscript.

\section{REFERENCES}

1 Centers for Disease Control and Prevention. Human papillomavirus (HPV) 2020 (cited 2020 Nov 12). Available from: https://www.cdc.gov/hpv/parents/about-hpv.html.

2 Vorsters A, Van Damme P, Bosch FX. HPV vaccination: are we overlooking additional opportunities to control HPV infection and transmission? Int J Infect Dis 2019; 88: 110-2.

3 World Health Organization. Human papillomavirus (HPV) and cervical cancer 2020 (cited 2020 Nov 12). Available from: https://www.who.int/news-room/fact-sheets/detail/human-papillomavirus-(hpv)-and-cervical-cancer.

4 López N, Torné A, Franco A, San-Martin M, Viayna E, Barrull C, et al. Epidemiologic and economic burden of HPV diseases in Spain: implication of additional 5 types from the 9-valent vaccine. Infect Agent Cancer 2018; 13: 15.

5 Gultekin M, Zayifoglu Karaca M, Kucukyildiz I, Dundar S, Boztas G, Semra Turan H, et al. Initial results of population based cervical cancer screening program using HPV testing in one million Turkish women. Int J Cancer 2018; 142: 1952-8.

6 Bruni L, Albero G, Serrano B, Mena M, Gómez D, Muñoz J, et al. Human Papillomavirus and Related Diseases in Turkey: Summary Report. ICO/IARC Information Centre on HPV and Cancer (HPV Information Centre) 2019.

7 Bruni L, Albero G, Serrano B, Mena M, Gómez D, Muñoz J, et al. Human Papillomavirus and Related Diseases in Europe: Summary Report. ICO/IARC Information Centre on HPV and Cancer (HPV Information Centre). 2019.

8 Williams WW, Lu PJ, Saraiya M, Yankey D, Dorell C, Rodriguez JL, et al. Factors associated with human papillomavirus vaccination among young adult women in the United States. Vaccine 2013; 31: 2937-46.

9 Bednarczyk RA, Birkhead GS, Morse DL, Doleyres H, McNutt LA. Human papillomavirus vaccine uptake and barriers: association with perceived risk, actual risk and race/ethnicity among female students at a New York State university, 2010. Vaccine 2011; 29: 3138-43.
10 Thompson EL, Vamos CA, Vazquez-Otero C, Logan R, Griner S, Daley EM. Trends and predictors of HPV vaccination among U.S. College women and men. Prev Med 2016; 86: 92-8.

11 Jeannot E, Viviano M, Follonier MC, Kaech C, Oberhauser N, Mpinga EK, et al. Human papillomavirus infection and vaccination: knowledge, attitude and perception among undergraduate men and women healthcare university students in Switzerland. Vaccines (Basel). 2019; 7: 130.

12 Cinar IO, Ozkan S, Aslan GK, Alatas E. Knowledge and behavior of university students toward human papillomavirus and vaccination. Asia Pac J Oncol Nurs 2019; 6: 300-7.

13 Oz M, Cetinkaya N, Apaydin A, Korkmaz E, Bas S, Ozgu E, et al. Awareness and knowledge levels of Turkish college students about human papilloma virus infection and vaccine acceptance. J Cancer Educ 2018; 33: 260-8.

14 Koc Z. University students' knowledge and attitudes regarding cervical cancer, human papillomavirus, and human papillomavirus vaccines in Turkey. J Am Coll Health 2015; 63:13-22.

15 Kessels SJ, Marshall HS, Watson M, Braunack-Mayer AJ, Reuzel R, Tooher RL. Factors associated with HPV vaccine uptake in teenage girls: a systematic review. Vaccine 2012; 30: 3546-56.

16 Altobelli E, Rapacchietta L, Profeta VF, Fagnano R. HPV-vaccination and cancer cervical screening in 53 WHO European Countries: an update on prevention programs according to income level. Cancer Med 2019; 8: 2524-34.

17 Hoque ME, Ghuman S, Hal GV. Human papillomavirus vaccination acceptability among female university students in South Africa. Asian Pac J Cancer Prev 2013; 14: 4865-9.

18 Rahman M, Islam M, Berenson AB. Differences in HPV immunization levels among young adults in various regions of the United States. J Community Health 2015; 40: 404-8.

19 You D, Han L, Li L, Hu J, Zimet GD, Alias H, et al. Human papillomavirus (HPV) vaccine uptake and the willingness to receive the hpv vaccination among female college students in China: a multicenter study. Vaccines (Basel) 2020; 8: 31. 
20 Allen JD, Mohllajee AP, Shelton RC, Othus MK, Fontenot HB, Hanna R. Stage of adoption of the human papillomavirus vaccine among college women. Prev Med 2009; 48: 420-5.

21 Dany M, Chidiac A, Nassar AH. Human papillomavirus vaccination: assessing knowledge, attitudes, and intentions of college female students in Lebanon, a developing country. Vaccine 2015; 33: 1001-7

22 Chiang VC, Wong HT, Yeung PC, Choi YK, Fok MS, Mak OI, et al. Attitude, acceptability and knowledge of HPV vaccination among local university students in Hong Kong. Int J Environ Res Public Health 2016;13: 486.

23 Cook RL, Zhang J, Mullins J, Kauf T, Brumback B, Steingraber $\mathrm{H}$, et al. Factors associated with initiation and completion of human papillomavirus vaccine series among young women enrolled in Medicaid. J Adolesc Health 2010; 47: 596-9.

24 Liddon NC, Leichliter JS, Markowitz LE. Human papillomavirus vaccine and sexual behavior among adolescent and young women. Am J Prev Med 2012; 42: 44-52.

25 Villanueva S, Mosteiro-Miguéns DG, Domínguez-Martís EM López-Ares D, Novío S. Knowledge, Attitudes, and Intentions towards Human Papillomavirus Vaccination among Nursing Students in Spain. Int J Environ Res Public Health 2019; 16: 4507 .
26 Agosti JM, Goldie SJ. Introducing HPV vaccine in developing countries-key challenges and issues. N Engl J Med 2007; 356: 1908-10.

27 Conroy K, Rosenthal SL, Zimet GD, Jin Y, Bernstein DI, Glynn S, et al. Human papillomavirus vaccine uptake, predictors of vaccination, and self-reported barriers to vaccination. J Womens Health (Larchmt) 2009; 18: 1679-86.

28 Dempsey A, Cohn L, Dalton V, Ruffin M. Patient and clinic factors associated with adolescent human papillomavirus vaccine utilization within a university-based health system. Vaccine 2010; 28: 989-95.

29 Widjaja VN. Awareness, knowledge and attitudes of human papillomavirus (hpv) among private university students-Malaysia perspective. Asian Pac J Cancer Prev 2019; 20: 2045-50.

30 Kang HS, Moneyham L. Attitudes toward and intention to receive the human papilloma virus (HPV) vaccination and intention to use condoms among female Korean college students. Vaccine 2010; 28: 811-6.

31 Tolunay O, Celik U, Karaman SS, Celik T, Resitoglu S, Donmezer $\mathrm{C}$, et al. Awareness and attitude relating to the human papilloma virus and its vaccines among pediatrics, obstetrics and gynecology specialists in Turkey. Asian Pac J Cancer Prev 2014; $15: 10723-8$ 